\title{
Produktivitas Sapi Bali Betina dan Hasil Persilangannya dengan Limousin dan Simmental yang di Pelihara Berbasis Pakan Hijauan di Kabupaten Keerom Papua
}

\author{
Productivity of Female Bali Cattle and their Crosses with Limousin and Simmental Based on Forage Feed \\ in Keerom District Papua
}

N. Kocu ${ }^{1}$, R. Priyanto ${ }^{2}$, Salundik ${ }^{2}$, \& Jakaria ${ }^{2}$

${ }^{1}$ Mahasiswa Pascasarjana Program Studi Ilmu Produksi Ternak, Fakultas Peternakan, IPB

${ }^{2}$ Departemen Ilmu Produksi dan Teknologi Peternakan, Fakultas Peternakan, IPB

Jln. Agatis, Kampus IPB Dramaga, Bogor, 16680, Indonesia

Email koresponden author: nikokocu@gmail.com

\begin{abstract}
Development of cattle in the Papua region still faces many obstacles, particularly the limited number of cattle population and the quality of the animal dominated by bali cattle. This study aimed to evaluate the productivity of bali cattle and their crosses with limousin and simental through artificial insemination. This study was carried out on December 2016 to February 2017 in the Arso and Skanto Districts, Keerom Regency, Papua. Ninty four heads of used in this study, comprising 57 bali catsle, 18 bali $x$ limousin and 19 bali $x$ simmental crosses through artificial insemination programe. Parameters vanahle included reproduction characteristics, body weight and linear body measurement. The observation were conducted of calf ( $<12$ month), young (13-24 month) and adult animal( $>25$ month). The results indicated that the female bali cattle and their crosses with limousin and simmental raised on forage based feed showed different reproduction and production perfomances. The cross bred cow (bali $x$ limousin and bali $x$ simmental) tended to have longer age at first mating, higher service per conception and lower calving rate. Based on forage feed, the cross bred cow had significantly $(\mathrm{P}<0.05)$ higher body weight and body frame size, particularly body weght, hip height, body lengt and heart girh at adult age. In general, the crosses between bali and limousin or simmental for cow-calf production could be developed on a forage based feed at Keerom District, Papua.
\end{abstract}

Keywords: bali cattle, crosses, forage, reproduction, production performance.

\section{PENDAHULUAN}

Populasi sapi potong di Indonesia secara nasional saat ini mencapai 16.599.247 ekor (Kementan 2017), dengan penyebaran sapi potong mulai dari barat pulau Sumatera sampai timur pulau Papua. Sapi lokal memiliki daya adaptasi yang sangat baik dengan iklim tropis di kawasan Timur Indonesia sehingga sapi bali dapat beradaptasi dan berkembang biak dengan baik di Provinsi Papua.

Sapi bali masuk pertama kali di Provinsi Papua melalui program Bantuan Presiden (Banpres) tahun 1970. Kabupaten Keerom, yang saat itu masih merupakan wilayah Kecamatan dari Kabupaten Jayapura, merupakan salah satu wilayah penyebaran ternak seiring dengan masuknya program transmigrasi di Provinsi Papua. Pengembangan sapi di wilayah Papua terutama Provinsi Papua masih mengalami banyak kendala terutama terbatasnya bibit sapi bali baik dari segi kuantitas maupun kualitas genetik.

Populasi ternak sapi tahun 2016 di Provinsi
Papua tercatat sebesar 116.913 ekor (Provinsi Papua dalam Angka 2017) dengan pusat pertumbuhan terdapat di Kabupaten Merauke dengan populasi 36.923 ekor, Keerom 19.444 ekor, Nabire 15.077 ekor dan Jayapura 15.064 ekor. Kabupaten Keerom merupakan salah satu wilayah pemekaran dari Kabupaten Jayapura, luas wilayah sebesar $9.365 \mathrm{~km}^{2}$ dengan jumlah penduduk 54.130 jiwa. Kabupaten ini dijadikan wilayah transmigrasi dimasa lampau sehingga terjadi transfer teknologi budidaya sapi dari masyarakat pendatang ke penduduk asli.

Sistem pemeliharaan sapi di Kabupaten Keerom menggunakan sistem intensif dan semi-intensif. Hal ini didukung dengan lahan luas dan penanaman rumput unggul yang dapat menunjang pemeliharaan sapi potong (Hendrawan 2002). Program inseminasi buatan (IB) masuk ke Papua pada tahun 1992. Namun, intensifikasi program IB berlangsung sejak tahun 2010 sampai sekarang dengan mengawinkan sapi bali yang menggunakan semen pejantan sapi bali, limousin dan simmental untuk meningkatkan penampilan produksi sapi lokal tersebut. Populasi sapi hasil persilangan melalui program IB di Kabupaten 
Keerom tercatat sebesar 823 ekor (Dinas Peternakan dan Kesehatan Hewan Provinsi Papua 2016). Namun demikian, belum tersedia informasi kinerja produksi dari sapi-sapi hasil persilangan IB yang dipelihara berbasis pakan hijauan.

Penelitian ini bertujuan untuk mengevaluasi produktivitas sapi bali dan hasil persilangannya dengan sapi limousin dan sapi simental yang dipelihara berbasis pakan hijauan di Kabupaten Keerom Papua.

\section{METODE PENELITIAN}

\section{Waktu dan Tempat Penelitian}

Penelitian ini telah dilaksanakan pada bulan Desember 2016 sampai Februari 2017 di Distrik Arso dan Skanto Kabupaten Keerom Provinsi Papua.

\section{Bahan dan Peralatan}

Bahan yang digunakan pada penelitian ini adalah sapi bali betina, sapi ballim dan sapi balsim hasil persilangan melalui perkawinan inseminasi buatan (IB) di Kabupaten Keerom berjumlah 57 ekor yaitu sapi bali betina 18 ekor, sapi ballim betina 20 ekor, sapi balsim betina 19 ekor.

Peralatan yang digunakan pada penelitian ini meliputi timbangan digital, pita ukur dan tongkat ukur.

\section{Prosedur Penelitian}

Pengumpulan data menggunakan metode survei dan wawancara secara langsung. Survei pengamatan terhadap ternak sapi bali, ballim dan balsim hasil persilangan melalui perkawinan inseminasi buatan. Data primer diperoleh dari survei lapang yaitu mengukur indikator tubuh dan penimbangan bobot hidup sapi bali, sapi ballim dan sapi balsim hasil persilangan inseminasi buatan. Data sekunder diperoleh dari Badan Statistik Kabupaten Keerom dan Dinas Pertanian, Peternakan dan Perikanan Kabupaten Keerom (BPS Keerom dalam Anggka 2016).

Sapi hasil persilangan inseminasi buatan yang digunakan adalah sapi bali, ballim dan balsim betina umur $\mathrm{I}_{0}, \mathrm{I}_{1}, \mathrm{I}_{2}$ dengan kisaran umur 1-3 tahun. Penentuan umur menggunakan rumus gigi berdasarkan catatan kelahiran dan pergantian gigi seri permanen (Standar Nasional Indonesia 2015).

\section{Peubah yang Diamati}

Sistem pemeliharaan berbasis pakan hijauan, karakteristik reproduksi, peubah bobot hidup (kg) sapi bali, ballim dan balsim diperoleh dengan ditimbang menggunakan timbangan digital. Ukuran linier tubuh (cm) yang diamati meliputi tinggi badan, tinggi pundak, panjang badan, lebar dada, dalam dada, lingkar dada, lebar kelangkang, lebar pinggul dan panjang kelangkang sapi bali, ballim dan balsim (Amano et al. 1981).

\section{Analisis Data}

Rancangan percobaan yang digunakan adalah rancangan acak lengkap (RAL) untuk membandingkan tiga bangsa sapi yaitu sapi bali, sapi bali dengan sapi limousin (ballim) dan sapi bali dengan sapi simental (balsim). Data yang diperoleh dianalisa dengan analisis ragam dengan model matematis sebagai berikut :

$$
Y i j k=\mu+\alpha i+\varepsilon i j
$$

Keterangan :

Yijk : Variabel respon bobot hidup dan ukuran linier tubuh pada bangsa ternak ke-i, dengan ulangan ke-j.

$\mu \quad$ : Rataan umum

ai $\quad$ : Pengaruh bangsa ternak ke-i

cij : Pengaruh galat silangan bangsa ternak ke-i dan ulangan ke-j

Selanjutnya untuk mengetahui perbedaan antar perlakuan maka di lanjutkan dengan uji lanjut menggunakan uji Duncan menurut (Matjjik dan Sumertajaya 2013).

\section{HASIL DAN PEMBAHASAN}

\section{Pemeliharaan Berbasis Pakan Hijauan}

Usaha peternakan sapi potong di Kabupaten Keerom umumnya berupa usaha pembiakan dengan bangsa ternak dominan berupa sapi bali, silangan sapi bali limousin dan silangan bali simental. Berdasarkan sistem pemeliharaan sapi di wilayah penelitian menggunakan sistem pemeliharaan secara intensif dan semi intensif. Pemeliharaan ternak secara intensif adalah pemeliharaan ternak sapi dikandangkan secara terus-menerus dengan pola pemberian pakan cut and carry. Sistem pemeliharaan semi intensif yaitu tenak dikandangkan pada malam hari dan dikeluarkan dari kandang siang hari namun sore hari sapi dimasukan kembali ke dalam kandang. Sistem pemeliharaan, pemberian pakan, pemberian air minum, penanganan kesehatan dan sistem perkawinan yang diterapkan pada lokasi penelitian ditampilkan pada Tabel 1.

Pakan adalah salah satu faktor yang sangat penting bagi kelangsungan hidup dari ternak. Sistem pemberian pakan umumnya hanya mengutamakan ketersediaan (jumlah dan kontinuitas) tanpa memperhitungkan kebutuhan dan kualitas pakan. Peternakan sapi potong di Kabupaten Keerom umumnya merupakan usaha semi intensif dengan pola penyediaan pakan yang dilakukan oleh peternak yaitu memanfaatkan sumber pakan yang tersedia seperti Pennisetum purpureum, King grass dan rumput lapang. Pola pemberian air minum berdasarkan bangsa ternak pada penelitian ini ditampilkan pada Tabel 1. Secara umum peternak dalam pemeliharaan sapi bali hanya memberikan air minum seperlunya, hal ini disebabkan sapi bali yang dipelihara lebih banyak digembalakan pada siang hari kemudian dikandangkan waktu sore hari. Pemberian air minum biasanya diberikan sebelum dan sesudah digembalakan. Berbeda dengan pemberian air minum pada bangsa sapi silangan bali limousin dan silangan bali simental diberikan ad libitum, hal ini dikarenakan kedua bangsa sapi silangan ini dipelihara secara intensif.

Penanganan kesehatan ternak sapi di lokasi penelitian ditangani langsung oleh pegawai peternakan dan petugas inseminator. Sistem perkawinan sapi bali di Kabupaten Keerom pada umumnya melalui kawin alam dan inseminasi buatan (IB). Peternak yang memiliki sapi umumnya ternak kawin secara alami tanpa memperhatikan bila ternak sapi betina muncul tanda-tanda birahi, selain 
Kocu et al.

Jurnal Ilmu Produksi dan Teknologi Hasil Peternakan 7 (1): 29-34

Tabel 1. Sistem pemeliharaan sapi di Distrik Arso dan Skanto Kabupaten Keerom

\begin{tabular}{lccc}
\hline \multirow{2}{*}{ Uraian } & Bali & Bangsa Sapi & Balsim \\
\cline { 2 - 4 } & Padang pengembalaan & Ballim & - \\
\hline Sistem Pemeliharaan & Kandang beratap & - & Kandang beratap \\
& Kandang terbuka & Kandang beratap & Kandang terbuka \\
& Rumput gajah & Kandang terbuka & Rumput gajah \\
Pemberian Pakan & Rumput raja & Rumput gajah & Rumput raja \\
& Rumput lapang & Rumput raja & Rumput lapang \\
Air Minum & Diberikan seperlunya & Rumput lapang & Ad-libitum \\
Penanganan Kesehatan & Pegawai peternakan Inseminator & Pegawai peternakan Inseminator & Pegawai peternakan Inseminator \\
Metode Perkawinan & Kawin Alami & - & - \\
& Inseminasi buatan & Inseminasi buatan & Inseminasi buatan \\
\hline
\end{tabular}

Keterangan; ballim = silangan bali limousin, balsim = silangan bali simental

itu dampak yang ditimbulkan banyak terjadi perkawinan sedarah (in-breeding). Berbeda halnya dengan bangsa sapi silangan di lokasi penelitian sepenuhnya sudah menerapkan inseminasi buaatan (IB), hal ini dilakukan kemungkinan sulitnya mencari pejantan unggul yang ada di lokasi. Kemajuan dalam teknologi peternakan melalui program yang telah memberikan manfaat nyata, program persilangan inseminasi buatan (IB) ini merupakan program yang perlu diikuti oleh peternak yang memelihara sapi betina perlu di IB.

\section{Karakteristik Reproduksi}

Penampilan reproduksi sapi bali, ballim dan balsim yang dipelihara berbasis hijauan di Kabupaten Keerom Provinsi Papua disajikan pada Tabel 2. Hasil penelitian menunjukkan bahwa sapi bali pertama dikawinkan pada rerata umur 18,6 bulan, sedangkan sapi ballim dan balsim umur pertama kali kawin yang lebih lama, yaitu masingmasing 21,8 bulan dan 21,3 bulan. Hal ini menunjukan bahwa sapi silangan ballim dan balsim masak lebih lambat dibandingkan sapi bali.

Nilai service per conception ditentukan oleh beberapa faktor diantaranya ketepatan mendeteksi birahi, kondisi ternak sendiri serta keterampilan dan ketepatan inseminator dalam pelaksanaan inseminasi (Pramono et al. 2008). Service per conception (S/C) sapi bali diperoleh 1,3 lebih rendah jika dibandingkan dengan sapi ballim 2,0 dan balsim 1,9. Semakin rendah nilai $\mathrm{S} / \mathrm{C}$ maka semakin tinggi tingkat fertilitas induk sapi tersebut. sebaliknya makin tinggi nilai $\mathrm{S} / \mathrm{C}$ maka makin rendah nilai kesuburan kelompok betina. Menurut Noor et al. (2001) keunggulan sapi bali memiliki tingkat fertilitas tinggi yaitu berkisar antara $80 \%-82 \%$. Service per conception pada penelitian ini masih berada dalam kisaran normal. Hal ini sesuai pendapat Toelihere (1981) yang menyatakan bahwa nilai $\mathrm{S} / \mathrm{C}$ yang normal berkisar antara 1,6 sampai 2,0. Hasil penelitian ini mengindikasikan bahwa pemeliharaan berbasis pemberian pakan hijauan pada sapi bali sangat adaptif, sementara bangsa silangan ballim dan balsim cukup adaptif karena masih berada dalam kisaran yang normal.

Lama bunting sapi bali pada penelitian ini diperoleh
Tabel 2. Penampilan reproduksi sapi bali, ballim dan balsim yang dipelihara berbasis pakan hijauan

\begin{tabular}{lccc}
\hline Parameter Reproduksi & \multicolumn{3}{c}{ Bangsa Sapi } \\
\cline { 2 - 4 } & Bali & Ballim & Balsim \\
\hline Umur kawin pertama (bulan) & 18,6 & 21,8 & 21,3 \\
Service per conception (S/C) & 1,3 & 2,0 & 1,9 \\
Lama bunting (hari) & 285 & 287 & 287 \\
Jarak beranak (bulan) & 12,2 & 12,9 & 12,6 \\
Anak lahir (\%) & 81,3 & 75,0 & 58,3 \\
Distokia (\%) & 23,1 & 41,7 & 21,4 \\
Anak mati (\%) & 4,0 & 5,6 & 2,4 \\
Dewasa mati (\%) & 1,61 & 1,61 & 3,2 \\
\hline Keteran
\end{tabular}

Keterangan: ballim $=$ silangan bali limousin, balsim $=$ silangan bali simental

285 hari, ballim dan balsim masing-masing 287 hari. Hasil penelitian ini mirip dengan hasil penelitian yang diperoleh Prasojo et al (2010) yang memperoleh lama kebuntingan sapi bali sebesar 284,4 hari. Sementara Devendra et al. (1973), menyatakan bahwa lama kebuntingan sapi berkisar 287 hari, sama dengan lama kebuntingan sapi hasil persilangan ballim dan balsim dari penelitian ini. Induk sapi bali pada penelitian ini memiliki tingkat kelahiran yang tinggi $81,3 \%$, dibandingkan dengan sapi ballim 75,0\% dan sapi balsim 58,3\%. Nilai tingkat kelahiran sapi bali tergolong tinggi sedangkan sapi ballim dan balsim tergolong sedang. Tonbesi et al. (2009), yang memperoleh tingkat kelahiran sapi bali yang dipelihara di Kabupaten Timor Tengah Utara dengan tingkat kelahiran 67,66\%. Romjali (2007) Sapi bali mempunyai keunggulan dibanding sapi potong lainnya yaitu tingkat reproduktivitas dan kesuburan (fertilitas) yang tinggi serta mampu beradaptasi dan berkembang di beberapa wilayah di Indonesia.

Indukan sapi bali yang termasuk dalam program IB di Distrik Arso dan Skanto Kabupaten Keerom Papua terjadi kasus distokia. Distokia yang terjadi langsung ditangani oleh petugas peternakan (inseminator) dilapangan. Kasus distokia yang terjadi pada induk sapi 
bali sebesar $23,1 \%$, sapi ballim $41,7 \%$ dan sapi balsim $21,4 \%$. Tingginya kasus distokia pada sapi bali diduga karena penggunaan semen pejantan bali dengan kerangka tubuh relatif besar, sementara pada sapi ballim dan balsim disebabkan penggunaan semen pejantan limousin dan simmental dengan ukuran kerangka tubuh besar. Faktor lain yang mempengaruhi distokia adalah hewan yang di kandangkan terus menerus dan tidak diberi kesempatan untuk bergerak terutama pada waktu bunting.

Hasil penelitian menunjukan bahwa jarak beranak sapi bali, ballim dan balsim masing-masing adalah 12,2 bulan, 12,9 bulan dan 12,6 bulan. Sudono (1983) jarak beranak induk sapi yang ekonomis tidak lebih dari 13 bulan. Untuk mencapai jarak beranak 12 bulan maka dalam waktu 60 hari induk sapi harus dikawinkan kembali karena fertilitas maksimum pada sapi terjadi 60-90 hari setelah beranak.

Tingkat kematian anak sapi pada penelitian ini masih dalam kategori yang rendah; kematian anak sapi bali, ballim dan balsim masing-masing sebesar 4,03\%, $5,64 \%$ dan $2,41 \%$. Kondisi induk yang cukup baik pada saat beranak mengindikasikan asupan pakan hijauan dapat memenuhi kebutuhan hidup pokok dan reproduksi sehingga kematian pedet relatif rendah. Tingkat kematian anak sapi bali yang relatif rendah juga dilaporkan oleh Tonbesi (2009), yaitu 5,42\%, serta hasil penelitian Samberi et al. (2010), pada anak sapi bali di Kepulauan Yapen Papua, yaitu 1,33\%. Sedangkan pada sapi dewasa memiliki tingkat kematian yang relatif rendah, pada sapi bali tercatat $1,61 \%$, sapi ballim $1,61 \%$ dan sapi balsim 3,22\%. Kematian ternak sapi adalah salah satu penghambat dalam usaha untuk meningkatkan populasi sapi potong. Tinggi rendahnya kematian ternak dalam suatu wilayah akan berpengaruh terhadap perkembangan populasi sapi di wilayah tersebut. Rendahnya tingkat kematian sapi dewasa dapat disebabkan oleh faktor manajamen pemeliharaan, pemberian pakan hijauan yang cukup dan teratur sehingga dapat menekan tingkat kematian sapi di Distrik Arso dan Skanto tersaji pada Tabel 2.

\section{Ukuran Linier Tubuh dan Bobot Hidup Sapi Betina Sapi Betina Anak}

Ukuran linear tubuh dan bobot hidup anak sapi bali, ballim dan balsim berdasarkan umur sapih sampai 12 bulan dengan sistem pemeliharaan intensif dan semi intensif ditampilkan pada Tabel 3. Hasil analisis statistik menunjukkan bahwa ukuran linier tubuh ketiga bangsa tidak menunjukkan perbedaan yang nyata $(\mathrm{P}>0,05)$. Namun bobot hidup bangsa sapi ballim anak secara statistik nyata berbeda $(\mathrm{P}<0,05)$ dibandingkan dengan bobot hidup sapi bali. Perbedaan ini disebabkan bangsa sapi ballim merupakan bangsa dengan kerangka tubuh besar sedangkan sapi bali merupakan bangsa sapi dengan kerangka kecil. Bobot hidup anak sapi ballim betina dipelihara secara intensif lebih tinggi $186,20 \pm 45,30 \mathrm{~kg}$ dibanding sapi bali yang dipelihara secara semi intensif $135,50 \pm 2,09 \mathrm{~kg}$. Menurut penelitian Hikmawaty (2014) bahwa identifikasi ukuran tubuh dan bentuk tubuh sapi bali di beberapa pusat pembibitan melalui pendekatan analisis komponen utama.

\section{Sapi Betina Muda}

Salah satu kriteria yang digunakan untuk mengetahui produktivitas ternak adalah dengan melihat ukuran linier tubuh dan bobot hidup. Rerata ukuran linier tubuh dan bobot hidup pada sapi bali, silangan ballim dan silangan balsim di Distrik Arso dan Skanto disajikan pada Tabel 3. Berdasarkan hasil analisis statistik menunjukkan bahwa ukuran linier tubuh pada bagian tinggi pinggul bangsa silangan balsim muda secara nyata berpengaruh $(\mathrm{P}<0,05)$ dibandingkan dengan bangsa silangan ballim. Tinggi pinggul silangan balsim pada umur 13-24 bulan yaitu $122,67 \pm 3,39 \mathrm{~cm}$, lebih tinggi dibandingkan dengan sapi bali $117,44 \pm 6,30 \mathrm{~cm}$, dan sapi ballim $114,83 \pm 6,73$ $\mathrm{cm}$. Faktor-faktor yang mempengaruhi ukuran linier adalah umur, kualitas pakan dan bangsa. Pertumbuhan dan perkembangan tulang tercapai sebelum ternak dewasa kelamin, setelah sapi mencapai dewasa kelamin pertumbuhan tulang akan terhenti karena osifikasi tulang rawan sudah sempurna (Field dan Taylor 2002).

\section{Sapi Betina Dewasa}

Ukuran linear tubuh yaitu tinggi pinggul, tinggi pundak, panjang badan, lebar dada, dalam dada, lingkar dada, lebar kelangkang, lebar pinggul, panjang kelangkang dan bobot hidup bangsa sapi bali, silangan ballim dan silangan balsim yang dipelihara secara intensif dengan semi intensif ditampilkan pada Tabel 3. Ukuran linier tubuh merupakan salah satu indikator untuk melihat tingkat produktivitas sapi (Kadarsih 2003). Hasil analisis statistik menunjukkan bahwa ukuran linier tubuh ketiga bangsa sapi tinggi pinggul, tinggi pundak, panjang badan, lingkar dada dan bobot hidup bangsa sapi ballim dan balsim dewasa lebih tinggi dan nyata berbeda $(\mathrm{P}<0,05)$ di bandingkan dengan sapi bali. Rerata bobot hidup sapi betina dewasa balsim $389,55 \pm 44,98 \mathrm{~kg}$, ballim 386,33 $\pm 29,39$, sapi bali $321,60 \pm 8,44 \mathrm{~kg}$. Perbedaan ini disebabkan bangsa sapi ballim dan balsim merupakan ternak dengan ukuran kerangka besar sedangkan sapi bali merupakan ternak dengan ukuran kerangka kecil. Hal ini sesuai dengan pendapat Handiwirawan et al. (1998), yang melaporkan bahwa ukuran tinggi pundak sapi bali lebih rendah dibandingkan dengan sapi persilangan brahbal, limbal, dan silangan simbal. Hasil penelitian ini pada bangsa sapi bali lebih tinggi dibandingkan dengan hasil yang diperoleh Hikmawaty et al. (2014) yang menemukan bobot badan sapi bali betina dewasa mencapai bobot 170-207,89 kg. Lebih lanjut Ni'am et al. (2012) menyatakan bahwa dengan bertambahnya bobot badan maka bertambah pula ukuran lingkar dada dan sebaliknya, bertambah lingkar dada maka bertambah pula bobot badan sesuai dengan umur, bobot hidup menunjukan volume dan tinggi pundak, tinggi pinggul, panjang badan dan lingkar dada sapi kerangka besar ballim dan balsim menunjukan tinggi.

\section{Bobot Badan Sapi Betina Anak, Muda, dan Dewasa}

Produktivitas seekor ternak erat kaitannya dengan faktor genetik, lingkungan dan umur. Performa seekor ternak tidak bisa ditampilkan jika lingkungan tidak sesuai. Bobot hidup sapi bali, ballim dan balsim ditampilkan pada Gambar 1. Berdasarkan kurva bobot badan pada penelitian ini menunjukkan bahwa bangsa silangan ballim memiliki 
Kocu et al.

Jurnal Ilmu Produksi dan Teknologi Hasil Peternakan 7 (1): 29-34

Tabel 3 Perbandingan ukuran linier tubuh sapi betina bali, ballim dan balsim berdasarkan kelompok umur

\begin{tabular}{|c|c|c|c|c|}
\hline \multirow[t]{2}{*}{ Umur (Umur) } & \multirow[t]{2}{*}{ Parameter pengamatan } & \multicolumn{3}{|c|}{ Bangsa Sapi } \\
\hline & & Bali & Ballim & Balsim \\
\hline \multirow[t]{9}{*}{$0-12$} & Tinggi Pinggul & $104,50 \pm 2,09$ & $108,00 \pm 4,74$ & $104,33 \pm 2,08$ \\
\hline & Tinggi Pundak & $109,00 \pm 2,94$ & $111,80 \pm 3,90$ & $110,67 \pm 1,54$ \\
\hline & Panjang Badan & $110,75 \pm 3,69$ & $113,40 \pm 4,03$ & $109,33 \pm 4,50$ \\
\hline & Lebar Dada & $27,50 \pm 2,09$ & $25,80 \pm 6,50$ & $27,33 \pm 4,16$ \\
\hline & Dalam Dada & $32,75 \pm 2,62$ & $28,80 \pm 7,30$ & $33,00 \pm 5,00$ \\
\hline & Lingkar Dada & $136,25 \pm 4,20$ & $137,80 \pm 11,19$ & $134,33 \pm 2,51$ \\
\hline & Lebar Kelangkang & $33,50 \pm 2,89$ & $30,00 \pm 4,07$ & $30,00 \pm 4,59$ \\
\hline & Lebar Pinggul & $32,75 \pm 2,99$ & $30,20 \pm 4,77$ & $31,33 \pm 6,42$ \\
\hline & Panjang Kelangkang & $35,75 \pm 2,88$ & $36,00 \pm 5,39$ & $30,33 \pm 2,08$ \\
\hline \multirow[t]{9}{*}{$13-24$} & Tinggi Pinggul & $117,44 \pm 6,30 \mathrm{ab}$ & $114,83 \pm 6,73 b$ & $122,67 \pm 3,39 a$ \\
\hline & Tinggi Pundak & $122,22 \pm 6,64$ & $120,50 \pm 5,75$ & $124,83 \pm 3,77$ \\
\hline & Panjang Badan & $130,11 \pm 6,68$ & $124,67 \pm 10,42$ & $132,83 \pm 7,68$ \\
\hline & Lebar Dada & $32,89 \pm 3,55$ & $30,17 \pm 3,98$ & $32,67 \pm 4,71$ \\
\hline & Dalam Dada & $36,55 \pm 2,88$ & $33,67 \pm 4,68$ & $34,00 \pm 5,51$ \\
\hline & Lingkar Dada & $156,67 \pm 7,39$ & $151,17 \pm 10,92$ & $156,50 \pm 14,72$ \\
\hline & Lebar Kelangkang & $36,11 \pm 1,70$ & $34,33 \pm 3,14$ & $37,17 \pm 5,74$ \\
\hline & Lebar Pinggul & $38,22 \pm 1,64$ & $35,83 \pm 2,79$ & $36,67 \pm 7,55$ \\
\hline & Panjang Kelangkang & $41,44 \pm 1,67$ & $40,67 \pm 3,50$ & $42,00 \pm 5,54$ \\
\hline \multirow[t]{9}{*}{ Dewasa $>25$} & Tinggi Pinggul & $114,00 \pm 1,00 \mathrm{~b}$ & $125.33 \pm 5,20 \mathrm{a}$ & $124,22 \pm 6,20 \mathrm{a}$ \\
\hline & Tinggi Pundak & $120,80 \pm 1,64 b$ & $131.00 \pm 4,82 \mathrm{a}$ & $129,67 \pm 4,88 \mathrm{a}$ \\
\hline & Panjang Badan & $133,20 \pm 0,83 b$ & $143 \cdot 11 \pm 6,33 \mathrm{a}$ & $142,67 \pm 7,15 \mathrm{a}$ \\
\hline & Lebar Dada & $31,40 \pm 1,14$ & $33.67 \pm 5,79$ & $34,11 \pm 4,34$ \\
\hline & Dalam Dada & $37,40 \pm 1,14$ & $37.22 \pm 5,01$ & $38,89 \pm 4,75$ \\
\hline & Lingkar Dada & $166,60 \pm 1,14 b$ & $177.78 \pm 3,45 \mathrm{a}$ & $177,44 \pm 10,81 \mathrm{a}$ \\
\hline & Lebar Kelangkang & $38,60 \pm 1,14$ & $40,78 \pm 4,52$ & $40,00 \pm 2,07$ \\
\hline & Lebar Pinggul & $40,80 \pm 1,30$ & $45,11 \pm 4,20$ & $43,89 \pm 5,13$ \\
\hline & Panjang Kelangkang & $45,20 \pm 2,39$ & $46,44 \pm 5,20$ & $47,78 \pm 2,69$ \\
\hline
\end{tabular}

Huruf pada baris yang sama menunjukkan perbedaan yang nyata $(\mathrm{P}<0,05)$.

bobot badan yang lebih tinggi dibandingkan dengan bangsa sapi bali dan silangan balsim pada umur anak 0-12 bulan. Perbedaan ini disebabkan karakteristik ukuran-ukuran tubuh dan bobot badan dari tetua sapi silangan masingmasing. Perbedaan bangsa akan memberikan keragaman pada kecepatan pertumbuhan sapi.

Berbeda halnya dengan sapi betina muda pada umur 13-24 bulan, dan sapi betina dewasa pada umur 25 bulan keatas menunjukkan bobot hidup bangsa sapi silangan balsim tertinggi dibandingkan dengan bangsa sapi silangan ballim dan sapi bali. Tingginya bobot hidup sapi silangan balsim disebabkan faktor bangsa. Sapi silangan balsim merupakan bangsa dengan ukuran tubuh yang besar sedangkan bangsa sapi bali merupakan tubuh dengan ukuran kecil. Kadarsih (2003) bahwa lingkar dada pada sapi yang berumur dewasa tubuh dapat digunakan sebagai peramal bobot badan dengan nilai determinasi, karena perbedaan bangsa akan memberikan keragaman pada kecepatan pertumbuhan sapi.

\section{KESIMPULAN}

Berdasarkan hasil penelitian dapat disimpulkan bahwa (1) Sapi silangan ballim dan balsim memiliki umur pertama kawin lebih lama, S/C lebih tinggi, serta persentase kelahiran anak yang rendah dibandingkan sapi bali. (2) Sapi ballim dan balsim memiliki ukuran kerangka tubuh yang lebih besar.

\section{Saran}

Sapi silangan ballim dan balsim bisa dikembangkan di wilayah yang berbasis pakan hijauan di Kabupaten Keerom Provinsi Papua.

\section{DAFTAR PUSTAKA}

Amano TM, Katsumata, Suzuki S. 1981. Morphological and genetical survey of water buffaloes in Indonesia. Grant-in-Aid for overseasscientific survey. The origin and phylogeny of Indonesian native livestock. Part II. The Research Group of Overseas Sci.

[Badan Pusat Statistik]. 2016. Keerom dalam angka. 


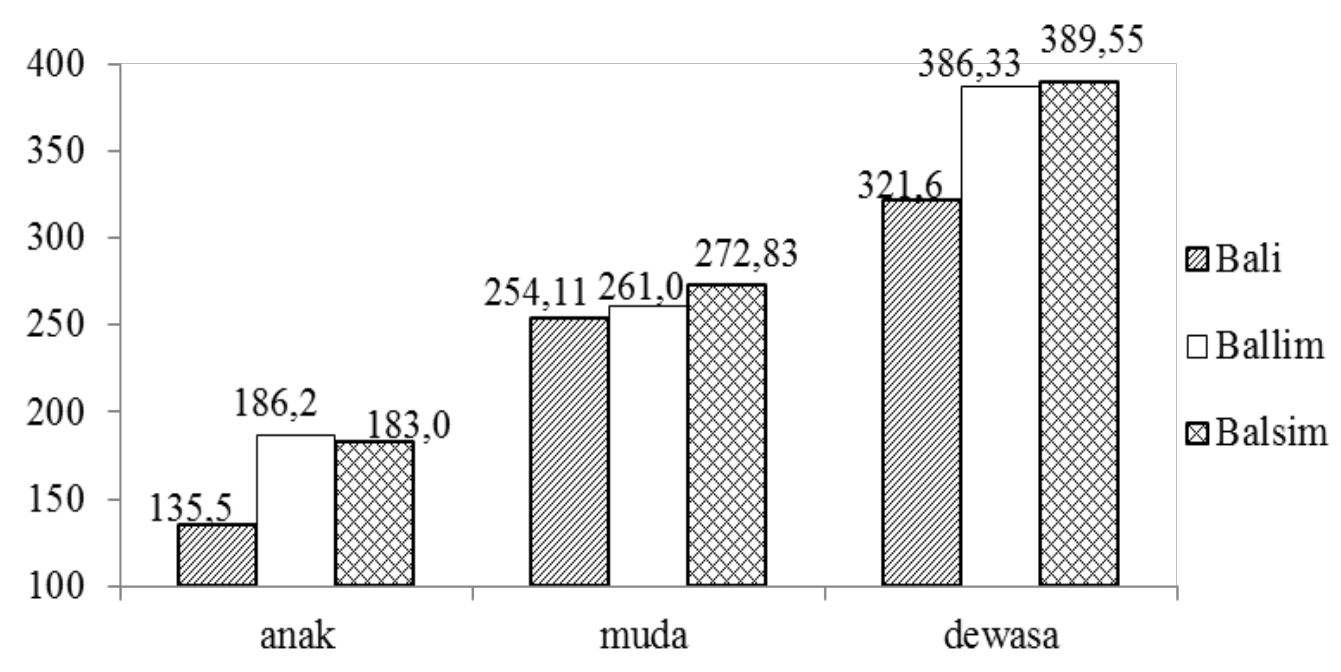

Gambar 1. Bobot hidup sapi betina anak, muda dan dewasa yang dipelihara berbasis pakan hijauan

Badan pusat statistik Kabupaten Keerom. J1. Poros Arso II, 99468.

Dinas Peternakan dan Kesehatan Hewan Provinsi Papua. 2016. Laporan populasi persilangan inseminasi buatan (IB) Sapi. Dinas peternakan Provinsi Papua. Jayapura.

Devendra CT, Lee KC, Pathmasingam. 1973. The productivity of bali cattle in Malaysia. J Agric 49:183-197.

Field TG, Tylor RE. 2002. Beef production and managemen decisions. 4th ed. prentice hall, new jersey.

Hikmawaty. 2014. Identifikasi ukuran tubuh dan bentuk tubuh sapi bali di beberapa pusat pembibitan melalui pendekatan analisis komponen utama. $J$ Ilmu Produksi dan Teknologi Hasil Peternakan. v. 02. (1): 231-237.

Hendrawan H, Salim R, Irawan R, Aminudin. 2002. Silase rumput lapang. teknologi sapi perah di Indonesia. Dairy Technology Improvement Project In Indonesia. Jawa Barat.

Handiwirawan E, Setiawan ED, Mathius IW, Santoso, Sudibyo A. 1998. Ukuran tubuh anak sapi bali dan persilangannya di Nusa Tenggara Barat. Prosiding seminar nasional peternakan dan veteriner. Bogor, 1-2 Desember 1998.

Kadarsih S. 2003. Peranan ukuran tubuh terhadap badan sapi Bali di Provinsi Bengkulu. J pen UNIB. 9 (1): 45-48.

Kementan. 2017. Kebijakan pemerintah dalam pembangunan peternakan sapi potong di Indonesia. Direktorat Jenderal peternakan dan kesehatan hewan (PKH) http:// ditjennak.pertanian.go.id/.

Mattjik AA, Sumertajaya IM. 2013. Perancangan percobaan dengan aplikasi SAS dan Minitab Jilid I. Bogor (ID): IPB Press.

Ni'am M, Purnomoadi A, Dartosukarno S. 2012. Hubungan antara ukuran-ukuran tubuh dengan bobot badan sapi bali betina pada berbagai kelompok umur. Anim agric 1 (1): 541-556.
Noor RR, Farajallah A, Karmita M. 2001. Pengujian kemurnian sapi bali dengan analisis hemoglobin dengan metode isoelectric focusing. Hayati 8:107-111.

Provinsi Papua Dalam Angka. 2017. Laporan tahunan. Dinas peternakan Provinsi Papua. (ID): [diunduh 2017 Agustus 17].

Prasojo G, Arifiantini IR, Mohamad K. 2010. Korelasi antara lama kebuntingan, bobot lahir dan jenis kelamin pedet hasil inseminasi buatan pada sapi bali. $J$ vet 11: 41-45.

Romjali E, Rasyid A. 2007. Keragaan reproduksi sapi bali pada kondisi peternakan rakyat di Kabupaten Tabanan Bali. Prosiding seminar nasional teknologi peternakan dan veteriner akselerasi agribisnis peternakan nasional melalui pengembangan dan penerapan IPTEK, pusat penelitian dan pengembangan Pertanian, Departemen Pertanian, Bogor, 21-22 Agustus 2007.

SNI [Standar Nasional Indonesia]. 2015. Bibit sapi potong - bagian 4 : Bali : SNI 7651. 4: 2015.

Samberi KY, Ngadiyono N, Sumadi. 2010. Estimasi dinamika populasi dan produktivitas sapi bali di Kabupaten Kepulauan Yapen, Provinsi Papua. Bul Peterna 34: 169-177.

Sudono A. 1983. Produksi sapi perah. Departemen ilmu produksi ternak. Fakultas Peternakan IPB. Bogor

Tonbesi TT, Ngadiyono N, Sumadi. 2010. Estimasi potensi dan kinerja sapi bali di Kabupaten Timor Tengah Utara, Propinsi Nusa Tenggara Timur. Bul peterna $33: 30-39$.

Toelihere MR. 1981. Fisiologi reproduksi pada ternak. Penerbit angkasa, Bandung. 